\title{
HUBUNGAN ANTARA HARGA DIRI DENGAN PELAKU PERILAKU PERUNDUNGAN SISWA KELAS VIII SMP N 2 TENGARAN 2017/2018
}

\author{
Retno Wulandari ${ }^{1}$, Yari Dwikurnaningsih ${ }^{2}$, Lobby Loekmono ${ }^{3}$ \\ Program Studi S1 Bimbingan dan Konseling Universitas Kristen Satya Wacana ${ }^{1}$ \\ Pascasarjana, Magister Manajemen Pendidikan Universitas Kristen Satya Wacana ${ }^{2}$ \\ Pascasarjana, Magister Manajemen Pendidikan Universitas Kristen Satya Wacana ${ }^{3}$ \\ (email):wulanr985@gmail.com ${ }^{1}$,yari.dwikurnaningsih@staff.uksw.edu ${ }^{2}$ \\ lobby.loekmono@staff.uksw.edu ${ }^{3}$
}

\begin{abstract}
Abstrak.
Penelitian ini dilaksanakan di SMP N 2 Tengaran, dengan populasi seluruh siswa kelas VIII yang berjumlah 101 orang siswa sebagai pelaku perilaku perundungan dan merupakan sampel total. Penelitian ini bertujuan untuk mengetahui signifikansi hubungan antara harga diri dengan pelaku perilaku perundungan siswa kelas VIII SMP N 2 Tengaran. Alat ukur yang digunakan dalam penelitian ini adalah Self-Esteem Inventory For Student yang disusun Coopersmith (1967) dan Olweus Bullying Questionnaire yang disusun Olweus (2003). Teknik analisis yang digunakan dalam penelitian ini adalah Kendall"s tau dengan program SPSS Version 21.0 for Windows. Hasil analisis data diperoleh hasil bahwa ada hubungan negatif yang signifikan antara harga diri dengan koefisien korelasi rxy = 0,177 dengan nilai sig (2-tailed) sebesar $0,011<0,05$. Artinya semakin rendah skor harga diri maka semakin tinggi skor pelaku perilaku perundungan, dan jika semakin tinggi skor maka semakin rendah pelaku perilaku perundungan.
\end{abstract}

Kata Kunci: Harga Diri, Pelaku Perilaku Perundungan

\begin{abstract}
.
This research was conducted in Tengaran Junior High School 2. It involved a population of all eighth grade students who numbered 101 students as bully doers and total samplings. This study aimed to determine the significance of correlation between self-esteem and bully doers of eighth grade students of Tengaran Junior High School 2. The measuring instrument used in this study was the Self-Esteem Inventory for Sudent compiled by Coopersmith (1967) and the Olweus Bullying Questionnaire compiled by Olweus (2003). The analysis technique used in this study was Kendall's Tau with SPSS Version 21.0 for Windows program. From data analysis results, it showed a significant negative correlation between self-esteem and coefficient correlation, rxy $=-0,177$ with a sig (2-tailed) value of $0.011<0.05$. This meant that the lower self-esteem score was, the higher the score of bully doers was. The higher the score was, the lower bully doers were.

Keywords: Self-esteem, Bully Doers

\section{PENDAHULUAN}

Perundungan atau yang lebih dikenal dengan istilah Bullying adalah

suatu perilaku yang dilakukan
seseorang secara berulang dengan
mengatakan atau melakukan sesuatu
hal dengan tujuan untuk menyakiti
\end{abstract}


orang yang lebih lemah atau sulit membela diri dari perilaku perundungan. Dapat disimpulkan perundungan adalah perilaku di mana terjadi ketidak seimbangan kekuatan di antara pelaku perundungan dan korbannya, sehingga dapat dikatakan bahwa pelaku perundungan selalu lebih kuat daripada korbannya, Bentuk dari tindakan perundungan dapat berupa perundungan fisik, verbal, psikologis, maupun Cyberbullying (Olweus, 2003).

United Nation International Children's Emergency Fund (UNICEF) pada 2016 merilis, bahwa perundungan di Indonesia berada pada peringkat pertama untuk kasus perundungan kepada anak. Kekerasan di sekolah, Indonesia menempati posisi pertama dengan 84\%. Jumlah lebih banyak dibandingkan negara Vietnam dan Nepal yang sama-sama tercatat $79 \%$, disusul kemudian Kamboja (73\%) dan Pakistan (43\%).

Dalam perundungan yang paling berkuasa adalah Pelaku. Pelaku perundungan pada umumnya memiliki ciri khas agresivitas yang tinggi, kurang memiliki empati dan harga diri, tidak memiliki rasa bersalah, dan merasa dirinya unggul (Olweus, 2005). Pelaku perundungan pada umumnya mempersepsikan dirinya memiliki kekuasaan untuk melakukan apa saja terhadap korbannya (Djuwita, 2005). Dengan demikian, bentuk-bentuk bantuan yang perlu diberikan kepada pelaku perundungan adalah menurunkan agresivitasnya dan meningkatkan empati dan harga dirinya.

Harga diri merupakan evaluasi yang dibuat oleh individu berdasarkan pada seberapa mampu mereka dalam menjalankan tugas, seberapa baik mereka memenuhi standart etis atau agama, seberapa besar mereka merasa dicintai dan merasa diterima oleh lingkungannya, dan seberapa besar pengaruh yang mereka miliki (Coopersmith, 2007).

Berdasarkan Pra Penelitian yang dilakukan pada siswa kelas VIII sebanyak 50 orang siswa ditemukan bahwa harga diri berada pada kategori rendah, yaitu $32 \%$, sedangkan untuk 
pelaku perilaku perundungan berada pada kategori tinggi, yaitu 38\%, Menurut Hasil studi yang dilakukan National Youth Violence Prevention Resource Center menunjukkan bahwa perundungan dapat membuat anak menjadi cemas dan ketakutan, mempengaruhi self esteem anak, meningkatkan isolasi sosial, memunculkan perilaku menarik diri, menjadikan anak rentan terhadap depresi dan stress, serta adanya rasa tidak aman., Dalam kasus yang lebih ekstrim, perundungan dapat mengakibatkan anak berbuat nekat, bahkan bisa membunuh maupun melakukan bunuh diri. Banks (1993) juga mengemukakan bahwa self esteem berkontribusi terhadap perilaku perundungan, tingginya depresi, dan tingginya tingkat kenakalan remaja.

Berdasarkan Latar belakang diatas maka rumusan masalah dalam penelitian ini adalah apakah ada hubungan antara harga diri terhadap pelaku perilaku perundungan siswa kelas VIII SMP N 2 Tengaran.

KAJIAN PUSTAKA

Pelaku Perilaku Perundungan
Perundungan adalah tindakan di mana terjadi ketidakseimbangan kekuatan di antara pelaku perundungan dan korbannya, sehingga dapat dikatakan bahwa pelaku perundungan selalu lebih kuat daripada korbannya, Bentuk dari tindakan perundungan dapat berupa fisik ( menendang, menjambak, memukul, menampar, memalak, meludah, dan hukumanhukuman fisik lainnya), perundungan verbal (menyebarkan sebuah gosip, memfitnah, meledek, mencaci maki, mempermalukan korban), perundungan psikologis (mengucilkan, ancaman, mendiamkan korban, meneror), maupun Cyberbullying (menjatuhkan reputasi seseorang dengan menyerangnya lewat media sosial, menjelekkan dengan kata-kata yang tidak pantas, menyebarkan fitnah terhadap korban). Pihak yang terlibat dalam perundungan diantaranya adalah pelaku yang biasanya paling berkuasa dalam tindakan perundungan.

Pihak-pihak yang terlibat dalam perilaku perundungan dibagi menjadi 3 yaitu: 
1. Bullies (pelaku bullying) yaitu individu yang secara fisik dan/atau emosional melukai individu lain secara berulang-ulang, karakteristik pelaku bullying biasanya adalah agresif, memiliki konsep positif tentang kekerasan, impulsif, dan memiliki kesulitan dalam berempati, (Olweus, dalam Moutappa dkk, 2004).

2. Victim (korban bullying) yaitu individu yang sering menjadi target dari perilaku agresif, tindakan yang menyakitkan dan hanya memperlihatkan sedikit pertahanan melawan penyerangnya (Olweus, dalam Moutappa dkk, 2004). Coloroso (2007) menyatakan korban bullying biasanya merupakan anak baru di suatu lingkungan, anak termuda di sekolah, biasanya yang lebih kecil, tekadang ketakutan, mungkin tidak terlindung, anak yang pernah mengalami trauma atau pernah disakiti sebelumnya dan biasanya sangat peka, menghindari teman sebaya untuk menghindari kesakitan yang lebih parah, dan merasa sulit untuk meminta pertolongan.

\section{Bystander (penonton)} merupakan orang yang menyaksikan tindakan bullying yang mungkin melakukan atau tidak melakukan sesuatu untuk menghentikan tindakan bullying tersebut. Bystander merupakan peran penting dalam kejadian bullying karena memiliki kesempatan untuk menghentikan bullying (Sullivan, 2000).

Menurut Olweus (2003), ada 5 faktor yang menyebabkan pelaku melakukan tindakan perundungan : 1) Pelaku pernah menjadi korban perundungam, 2) Balas Dendam, 3) Menunjukkan Eksistensi diri, 4) Ingin mendapatkan pengakuan, 5) Menutupi kekurangan yang dimilikinya.

\section{Harga Diri}

Menurut Coopersmith (2007) harga diri ialah hasil dari evaluasi individu terhadap diri sendiri yang diapresiasikan dalam sikap terhadap diri sendiri. Evaluasi ini menyatakan bahwa suatu sikap penerimaan atau penolakan dan menunjukkan seberapa besar individu percaya bahwa dirinya mampu, berhasil, berarti, berharga menurut standar dan nilai pribadinya. Dalam harga diri terdapat 2 tingkatan, yaitu individu yang memiliki harga diri 
yang positif yaitu individu yang menganggap dirinya sebagai orang yang berharga dan sama baiknya serta dapat menerima kritik dengan baik. Sedangkan individu yang memiliki harga diri yang negatif, ia akan cenderung menganggap dirinya sebagai orang yang berharga sehingga takut gagal, merasa dirinya rendah, kurang menerima kritikan, tidak menyukai sesuatu hal yang baru, dan kurang memiliki sikap yang demokratis.

Adapun aspek Pembentukan Harga diri menurut Coopersmith (2007) diantaranya adalah 1) Kekuatan (Power)yaitu Kemampuan untuk mempengaruhi dan mengontrol oranglain dan mengontrol dirinya sendiri. Pada situasi tertentu individu ditunjukkan dengan penghargaan dan penghormatan dari oranglain, 2) Kebajikan (Virtue) yaitu Ketaatan pada nilai moral, etika, dan aturan-aturan yang ada dalam masyarakat. Seseorang yang taat pada aturan-aturan dan ketentuan ketentuan yang ada dalam masyarakat akan mempunyai perasaan berharga dan bangga pada diri sendiri,
3) Keberartian (Significance) yaitu Keberartian individu dalam lingkungan. Individu akan merasa berarti jika ada penghargaan, penerimaan, perhatian, dan kasih sayang dari orang-orang terdekat seperti keluarga, sahabat, atau masyarakat, 4) Kompetensi (Competence) yaitu Kompetensi untuk mencapai apa yang dicita-citakan atau diharapkan. Hal ini berhubungan dengan kompetensi yang dimiliki individu, dengan adanya kompetensi yang cukup individu merasa yakin untuk mencapai apa yang dicitacitakan dan mampu mengatasi setiap masalah yang dihadapinya.

\section{METODE PENELITIAN}

Metode dalam penelitian ini adalah penelitian kuantitatif berjenis korelasional. Penelitian ini dilakukan untuk mengetahui hubungan antara variabel harga diri dengan variabel pelaku perilaku perundungan. Variabel dalam penelitian ini adalah Harga Diri (X) dan Pelaku Perilaku Perundungan (Y).

Populasi dalam penelitian ini adalah seluruh siswa kelas VIII yang 
menjadi Pelaku Perilaku Perundungan yang berjumlah 101 orang siswa, yaitu kelas VIII A yang berjumlah 34 orang siswa, kelas VIII B 32 orang siswa, kelas VIII C 32 orang siswa, kelas VIII D 32 orang siswa, kelas VIII E 32 orang siswa, kelas VIII F 32 orang siswa, kelas VIII G 32 orang siswa, kelas VIII H 33 orang siswa, dan kelas VII I 32 orang siswa. Sampel yang digunakan dalam penelitian ini adalah total sampling yaitu pengambilan sampel yang sama dengan jumlah populasi yang ada, Jumlah sampel yang diambil dalam penelitian ini adalah 101 orang siswa yang berperan sebagai pelaku perundungan.

Instrumen pengumpulan data yang digunakan adalah Self-Esteem Inventory for Student untuk mengukur Harga diri dan Olweus Bullying Questionnaire untuk mengukur Pelaku Perilaku Perundungan.

\section{HASIL DAN PEMBAHASAN}

Deskripsi klasifikasi distribusi frekuensi Harga Diri siswa kelas VIII SMP N 2 Tengaran dikategorikan menjadi 5 kategori dengan rumus i= skor max-skor min dibagi dengan kategori. Skor maximum untuk harga diri adalah $30 \times 4=120$ dan skor minimum $30 \times 1=30 . \mathrm{i}=120-30: 5=18$. Analisis deskriptif Harga Diri siswa kelas VIII SMP N 2 Tengaran dilaporkan pada tabel berikut

Tabel 1 Deskripsi Harga Diri Siswa Kelas VIII SMP N 2 Tengaran

\begin{tabular}{|l|l|l|l|}
\hline Kategori & Interval & Frekuensi & Prosentase \\
\hline $\begin{array}{l}\text { Sangat } \\
\text { Rendah }\end{array}$ & $30-47$ & 6 & $5,9 \%$ \\
\hline Rendah & $48-65$ & $\mathbf{5 5}$ & $\mathbf{5 4 , 4 \%}$ \\
\hline Sedang & $66-83$ & 30 & $29,7 \%$ \\
\hline Tinggi & $84-101$ & 14 & $13,8 \%$ \\
\hline $\begin{array}{l}\text { Sangat } \\
\text { Tinggi }\end{array}$ & $102-$ & 1 & $0,9 \%$ \\
\hline Jumlah & 120 & 101 & $100 \%$ \\
\hline
\end{tabular}

Dari tabel 1 Harga Diri siswa

kelas 8 SMP N 2 Tengaran sebagian besar berada pada kategori Rendah $(54,4 \%)$.

Deskripsi klasifikasi distribusi frekuensi Pelaku Perilaku Perundungan siswa kelas VIII SMP N 2 Tengaran dikategorikan menjadi 5 kategori dengan rumus $\mathrm{i}=$ skor maxskor min dibagi dengan kategori. Skor maximum $30 \times 4=120$, skor minimum $30 \times 1=30$. $i=120-30: 5=18$ Analisis deskriptif Pelaku Perilaku 
Perundungansiswa kelas VIII SMP N 2

Tengaran dilaporkan pada tabel berikut

Tabel 2. Deskripsi Pelaku Perilaku Perundungan Siswa Kelas VIII SMP N 2 Tengaran

\begin{tabular}{|l|l|l|l|}
\hline $\begin{array}{l}\text { Kategor } \\
\mathrm{i}\end{array}$ & $\begin{array}{l}\text { Interva } \\
1\end{array}$ & $\begin{array}{l}\text { Frekuens } \\
\mathrm{i}\end{array}$ & $\begin{array}{l}\text { Prosenta } \\
\text { se }\end{array}$ \\
\hline $\begin{array}{l}\text { Sangat } \\
\text { Rendah }\end{array}$ & $30-47$ & 1 & $0,9 \%$ \\
\hline Rendah & $48-65$ & 2 & $1,9 \%$ \\
\hline Sedang & $66-83$ & 39 & $38,6 \%$ \\
\hline Tinggi & $84-101$ & $\mathbf{5 6}$ & $\mathbf{5 5 , 4 \%}$ \\
\hline $\begin{array}{l}\text { Sangat } \\
\text { Tinggi }\end{array}$ & $\begin{array}{l}102- \\
120\end{array}$ & 3 & $2,9 \%$ \\
\hline Jumlah & 101 & $100 \%$ \\
\hline
\end{tabular}

Dari tabel 2 Sebagian besar

Pelaku Perundungan siswa kelas 8 SMP N 2 Tengaran berada pada kategori Tinggi $(55,4 \%)$.

Analisis korelasi antara harga diri dengan pelaku perilaku perundungan menggunakan uji korelasi Kendall'Tauu diperoleh hasil sebagai berikut

Tabel 3 Korelasi antara Harga Diri dengan Pelaku Perilaku Perundungan

\begin{tabular}{|c|c|c|c|c|}
\hline \multicolumn{3}{|c|}{ Correlations } & $\begin{array}{l}\text { peru } \\
\text { ndun } \\
\text { gan }\end{array}$ & $\begin{array}{c}\text { Harga } \\
\text { Diri }\end{array}$ \\
\hline $\begin{array}{l}\text { Kendal } \\
\text { l's } \\
\text { tau_b }\end{array}$ & $\begin{array}{l}\text { Pelak } \\
\text { u } \\
\text { Perila } \\
\text { ku } \\
\text { Perun } \\
\text { dunga } \\
\mathrm{n}\end{array}$ & $\begin{array}{l}\text { Correlat } \\
\text { ion } \\
\text { Coeffici } \\
\text { ent } \\
\text { Sig. (2- } \\
\text { tailed) } \\
\text { N }\end{array}$ & $\begin{array}{l}1.00 \\
0\end{array}$ & $\begin{array}{l}- \\
.177^{*} \\
.011 \\
101\end{array}$ \\
\hline & $\begin{array}{l}\text { harga } \\
\text { _Diri }\end{array}$ & $\begin{array}{l}\text { Correlat } \\
\text { ion } \\
\text { Coeffici } \\
\text { ent } \\
\text { Sig. (2- } \\
\text { tailed) } \\
\text { N }\end{array}$ & $\begin{array}{l}- \\
.177^{*} \\
.011 \\
101\end{array}$ & $\begin{array}{l}1.00 \\
0\end{array}$ \\
\hline
\end{tabular}

Dari tabel uji korelasi tabel 3 diketahui koefisien korelasi antara harga diri dengan pelaku perilaku perundungan yaitu $\mathrm{rxy}=-0,177$ dengan nilai sig (2-tailed) sebesar 0,011<0,05, sehingga dapat disimpulkan bahwa ada hubungan yang signifikan dengan arah negatif antara variabel harga diri dengan variabel pelaku perilaku perundungan, artinya semakin tinggi skor harga diri maka semakin rendah skor pelaku perilaku perundungan, semakin rendah skor harga diri maka semakin tinggi skor pelaku perilaku perundungan. 
Dari tabel uji korelasi diketahui koefisien korelasi antara harga diri dengan pelaku perilaku perundungan yaitu $\mathrm{rxy}=\quad-0,177$ dengan nilai sig (2-tailed) sebesar 0,011<0,05 sehingga dapat disimpulkan bahwa ada hubungan yang signifikan dengan arah negatif antara variabel harga diri dengan variabel pelaku perilaku perundungan, Pelaku Perilaku Perundungan dalam penelitian ini juga berada pada kategori Tinggi yaitu $55,4 \%$ dan Harga diri berada pada kategori Rendah yaitu 54,4\% artinya harga diri ada hubungannya dengan pelaku perilaku perundungan, karena seseorang yang memiliki harga diri rendah menjadikan anak kurang menerima keberadaan dirinya dan tidak menghargai dirinya, harga diri yang rendah memunculkan kecenderungan perilaku agresif dalam diri anak dan perilaku anak akan cenderung muncul untuk mencari perhatian seperti ingin dicap sebagai jagoan, menginginkan kekuasaan disekolah atau memang memiliki hasrat untuk menyakiti oranglain.
Menurut

Christhoporus, Stefanus \& Praharesti (2008) dalam penelitiannya juga menjelaskan bahwa anak yang memiliki harga diri yang rendah menjadi kurang menerima keberadaan dirinya dan tidak menghargai dirinya. Harga diri yang rendah memunculkan kecenderungan perilaku agresif dalam diri anak. Dengan adanya harga diri yang rendah, perilaku anak akan cenderung muncul untuk mencari perhatian seperti ingin dicap sebagai jagoan, menginginkan kekuasaan di sekolah atau memang memiliki hasrat untuk menyakiti orang lain. Sedangkan anak yang memiliki harga diri yang tinggi mampu menerima keberadaan dirinya dan mengakui akan kemampuan yang dimilikinya, dan ini membuat siswa mampu memilah mana perbuatan yang baik maupun yang buruk. Anak dapat menjaga perilaku agar tidak melukai atau menyakiti oranglain.

Menurut Coopersmith (2007) individu dengan harga diri yang tinggi memiliki keyakinan akan kemampuannya, lebih mudah menyesuaikan diri dengan suasana 
yang menyenangkan sehingga tingkat kecemasannya rendah serta memiliki ketahanan diri yang seimbang. Jika seseorang dapat mengembangkan harga dirinya dengan baik, maka ia dapat terhindar dari perilaku negatif bullying.

Hasil penelitian ini sejalan dengan penelitian Vintyana (2015) dengan judul "Hubungan Antara Harga Diri dan Kecenderungan Perilaku Bullying pada siswa SMP Kristen 1 Magelang" dengan responden berjumlah 101 orang siswa menunjukkan hasil koefiensi korelasi sebesar $r_{x y}=-0.349$ dengan signifikansi $\mathrm{p}=0,000(\mathrm{p}<0,05)$, yang artinya ada hubungan negatif signifikan antara harga diri dengan kecenderungan perilaku bullying pada siswa SMP Kristen 1 Magelang. Adanya kesamaan hasil penelitian dikarenakan subjek penelitian sama yaitu siswa SMP dan teori yang digunakan juga sama yaitu untuk harga diri menggunakan Coopersmith (1976) dan untuk Perundungan menggunakan teori dari Olweus (2003).
Berbeda dengan penelitian yang dilakukan oleh Erniati (2017) dengan judul "Hubungan Antara Harga Diri dengan Perilaku Bullying pada Remaja di SMP Muhammadiyah 2 Gamping Sleman Yogyakarta" dengan sampel berjumlah sebanyak 97 orang siswa, Menunjukkan hasil tidak ada hubungan yang signifikan antara harga diri dengan perilaku bullying pada remaja di SMP Muhammadiyah 2 Gamping Sleman Yogyakarta dengan nilaikoefisien korelasi sebesar $r_{x y}=$ 0.035 dan $p($ value $)=0,725>0,05$.

\section{SIMPULAN DAN SARAN}

Kesimpulan

Hasil penelitian ini menunjukkan ada hubungan negatif yang signifikan antara harga diri dengan pelaku perilaku perundungan, yang artinya apabila skor harga diri turun maka skor pelaku perilaku perundungan naik atau apabila skor harga diri naik maka skor pelaku perilaku perundungan turun.

\section{Saran}

\section{Bagi Guru BK}


Hasil penelitian menunjukkan adanya hubungan yang signifikan dengan arah negatif antara harga diri dengan pelaku perilaku perundungan siswa kelas VIII di SMP $\mathrm{N} 2$ Tengaran. Guru Bimbingan dan Konseling disarankan agar memberikan layanan kepada siswa yang menjadi pelaku perilaku perundungan yang berada pada kategori tinggi $(55,4 \%)$, supaya tidak melakukan perilaku perundungan yang merugikan bagi oranglain, sesuai dengan item pernyataan nomor 4 (Saya sering memberi julukan tidak pantas kepada teman saya), item nomor 13 ( Saya pernah menampar dengan kepada teman saya), dan item nomor 27 ( Saya pernah memaki teman di status facebooknya).

Selain kepada pelaku perilaku perundungan, Guru BK diharapkan memberikan layanan kepada korban perundungan untuk meningkatkan perilaku asertifnya, sehingga siswa dapat menumbuhkan kepercayaan diri dan harga diri sehingga dapat menekan perilaku perundungan.
Sedangkan untuk harga diri yang berada pada kategori rendah (54,4\%), Guru BK diharapkan memberikan layanan agar siswa dapat meningkatkan harga dirinya.

\section{Bagi Peneliti Selanjutnya}

Setelah dilakukan analisis korelasi ditemukan hasil bahwa harga diri berkorelasi signifikan dengan pelaku perilaku perundungan dengan arah negatif. Bagi peneliti selanjutnya diharapkan dapat menggunakan variabel lain, dikarenakan peneliti hanya berfokus kepada pelaku, sehingga dapat diketahui variabel apa saja yang memiliki hubungan yang signifikan dengan harga diri, misalnya dengan variabel korban, bystander perilaku perundungan maupun cyberbullying.

\section{DAFTAR PUSTAKA}

Banks. 1993. Multicultural Education: Historical Development, Dimensions, and Practice. Seattle: University of Washington

Christhoporus, Stefanus, Praharesti. 2018. Perilaku Bullying 
Ditinjau dari Harga Diri dan

Pemahaman Moral Anak.

Jurnal IKIP PGRI Semarang,

Unika Soegijapranata

Semarang

Coloroso, Barbara. 2007. Penindas,

Tertindas, dan Penonton, Resep Memutus Rantai Kekerasan Anak dari Prasekolah Hingga SMU.

Jakarta: Serambi

Coopersmith, Stanley. 2007. The Antencendendents of Self Esteem. Amerika Serikat: Consulting Psychologists Press

Djuwita, R. 2005. Peranan Faktor Personal dan Situasional Terhadap Perilaku Bullying di Kota Besar di Indonesia (Laporan Penelitian). Jakarta: Universitas Indonesia

Erniati, Wahyu. 2017. Hubungan Harga Diri Dengan Perilaku Bullying pada Siswa di SMP Muhammadiyah 2 Gamping Sleman Yogyakarta. Ilmu
Keperawatan.

Fakultas

Kesehatan

Universitas

'Aisyiyah Yogyakarta

Moutappa, M., Valente, T., Gallaher, P., Rohrbach, L.N. \& Unger, J.B. 2004. Social Network Predictors of Bullying and Victimization. Adolescence Journal, Vol 3. 39, No. 154, p. 315-336

Olweus, Dan. 2003. Bullying at School. USA: Blackwell Publishing

Olweus, Dan. 2005. Bullying at School: What We Know and What We Can Do. Oxford: Blackwell Publishing

Sindo. 2016. Indonesia Tempati Posisi Tertinggi di ASEAN. (Online). Diakses tanggal 2 Mei 2018. Website: http://nasionalsindonews.com/read/1223442/1 5/indonesia tempati-posisitertinggi-perundungan-diasean-1500880739 
Sullivan, K. 2000. The anti-bullying handbook. New York: Oxford University. Press

Vintyana, Serafika. 2015. Hubungan Antara Harga Diri dengan
Kecenderungan Perilaku Bullying Pada Siswa SMP Kristen 1 Magelang. Psikologi. Fakultas Psikologi Universitas Kristen Satya Wacana Salatiga 